\section{Организация и развитие коллекционных фондов на основе СУБД Access}

\author{
А. В Кузьмин ${ }^{1}$ \\ Л. И. Кузьмина \\ Е. С. Ольхина \\ Ю. В. Ольхин \\ ПАБСИ КНЦ РАН \\ Петрозаводский государственный университет
}

В статье приведены результаты создания базы данньх на основе Access 2 по коллекционньм фондам растений Полярно-альпийского ботанического садаинститута. Отмечены возможности поиска необходимой информации, внесения новьх и редактирова́ния существующих данньх.

Ключевые слова: коллекционные фонды растений, база данных, формы.

\section{ВВЕДЕНИЕ}

Развитие коллекционньгх фондов в ботанических садах сопровождалось накоплением обширного количества разнообразньх исходньх данньх. Огромные массивы эмпирической информации, хранящиеся в виде набора карточек, делают задачу проведения необходимых обобщений весьма трудоемкой и во многих случаях нецелесообразной. Поэтому надежное хранение важной информации с последующей организацией ее эффективного использования на современном уровне весьма актуально. Эти задачи призваны решать базы данньх (БД) реляционного типа с широким использованием возможностей вычислительной техники. Применение современньг персональньх компьютеров позволяет успешно решать проблемы систематизированного хранения исходной информации, обмена, селекции данньх, рацнональной обработки и создания различньх форм представления, включая графические [1].

Оболочка Access, версии 2 - одна из современньх средств управления базами данньх (СУБД). Краткое методическое пособие [2] позволяет за короткий период освоить некоторые основные способы создания и управления БД. В комплект поставки Access входят базы данньх примеров, которые не только помогают разобраться с организацией данных, но и сами служат богатым источником идей при создании собственных баз данных. Отличительной особенностью указанной системы управления БД являются широкие возможности по созданию различньгх форм

\footnotetext{
${ }^{1}$ Авторы - соответственно зав. отделом экономики ПАБСИ, инженер ПАБСИ, аспирант ПАБСИ и инженер ПетрГУ

() А. В. Кузьмин, Л. И. Кузьмина, Е. С. Ольхина, Ю. В. Ольхин, 1999
}

отчетности, что позволяет хранить информацию в удобной для исследователя форме и создавать различные таблицы, графики для обмена, не затрагивая исходной БД.

Как и любая БД, Access хранит данные в таблицах. Важнейшим дополнением к ним являются запросы, позволяющие организовать быстрый доступ к хранящимся в БД таблицам. С их помощью можно сортировать исходные таблицы по любому полю, задавая предварительно условия отбора или сводить вместе данные из нескольких связанных таблиц. Количество сформированных запросов не будет влиять на размер БД. Кроме того, представляются широкие возможности наглядной демонстрации данных посредством форм и отчетов. Преимуществом форм является то, что в них можно отобразить всю информацию, содержашуюся в каждой записи, в то время как в режиме таблицы часть полей может выходить за пределы экрана. При помощи форм можно производить ввод новых и редактирование существующих данньх, а также воспользоваться возможностями, предоставляемыми графической средой Windows (различные шрифты, графика и т. д.). Для вывода данных на печать предназначены отчеты. Access обеспечивает доступ к другим популярньм базам данных (DBase IV, FoxPro, Paradox и др.) [3], электронным таблицам и даже к данньм текстовых файлов.

В ПАБСИ была предпринята попытка создания БД на основе картотеки, состоящей из отдельных стандартньх бланков, заполняемьх вручную на каждое наблодаемое растение. В качестве примера использовалась коллекция растений, включающая древесные виды. Картотека на каждое растение содержит многочисленные данные описательного характера, ежегодные фенологические наблюдения и данные по инвентаризации. Решено было создать 3 таблицы: в 1 таблице предполагалось хранить перечень растений с их подробным описанием, во 2 - данные по инвентаризации каждого растения и в 3 - фенологические данные. Access предоставляет возможность русского обозначения полей и названия самих таблиц, поэтому первую таблицу мы назвали "Каталог", вторую "Инвентаризация", третью - "Фенология". В таблицу "Каталог" вошли следующие поля:

1. Код растения; 2. Название растения; 3. Инвентаризационный номер; 4. Жизненная форма; 5. Семейство; 6. Род; 7. Вид; 8. Синонимы; 9. Ареал; 10. Происхождение; 11. Посев или посадка; 12. Появление всходов; 13. Пикировка или пересадка; 14. Местопроизрастание; 15 . Примечание.

Для полей, в которые предполагается внесение больших текстов, тип данньх - текстовой или мемо. При создании структуры таблицы надо знать, по каким полям будет проводиться сортировка, их необходимо обозначить индексами. Это значительно ускорит работу с большими таблицами. В нашем случае это поля за номерами $1,2,5,6,7$. Следующая таблица - 
"Инвентаризация", в ней тоже есть поле, совпадающее с полем "Код растеняя". Но если в "Каталоге" оно обозначено первичньм ключом, тип данных счетчик (индексное поле, в котором не допускаются совпадения), то в "Инвентаризации" оно обозначено вторичньм ключом, тип данньх - числовой, длинное целое (индексное поле, в котором совпадения допускаются). В полях, по которым будут проводиться вычисления, устанавливаются числовые. Аналогично составлена и таблица "Фенология". В полях, обозначающих определенные фенофазы, календарные даты переведены в числовые коды, чтобы в дальнейшем можно было проводить вычисления. Между совпадающими полями во всех таблицах установлена связь типа "один - ко - многим". Таким образом, одной записи (растению) в "Каталоге" соответствует несколько записей в "Инвентаризации" и "Фенологии". Структура таблиц задана таким образом, что очередность внесения данных по годам не имеет значения. В нашем случае в индексньх полях "Код растения", "Название", "Семейство", "Род", "Вид" в таблице "Каталог" и "Код растения" и "Годы" в таблицах "Инвентаризация" и "Фенология" установлена сортировка по возрастанию. Поэтому при внесении новых данных по растениям названия будут располагаться в алфавитном порядке, а годы наблюдения - по возрастанию. Структуру таблицы необходимо изначально тщательно проработать перед внесением своих данньх, пстому что, например, изменение размера поля в меньшую сторону в дальнейшем может привести к потере информации. Схематичное представление структуры БД на начальном этапе ее создания демонстрируется на рисунке 1. Стрелка указывает направление потока информации, сплошная линия объединяет элементы базы, на которые действуют макросы.

После формирования трех таблиц было проведено их связывание простым приемом "буксировки" одноименного поля "Код растения". Направление буксировки изображено на рисунке двумя стрелками. Для свойств поля "Код растения" в двух последних таблицах установили вместо счетчика числовой тип данных, длинное целое. Затем сохранили макет связей между таблицами как объединение типа "один - ко многим".

Используя запросы, можно выбирать и обрабатывать хранящуюся в таблицах информацию. Мы сформировали запрос ко всем трем таблицам, в котором присутствуют поля 2, 5, 6, 7 из "Каталога" и интересующие нас поля из 2 и 3 таблицы. Причем, чтобы выбрать записи по интересующему нас растению или группе растений определенного семейства, достаточно в конструкторе запроса в условиях отбора по этим полям ввести образец поля и начальные буквы с символом "звездочка" (*). Затем мы сформировали запрос, чтобы получить средние значения наступления фенофаз за период наблюдений. Поэтому для интересующих нас полей в конструкторе запроса в строке групповые операции мы поставили Avg для остальных группировка. В результате выполнения запроса мы получили группировку растений по названию (семейство, род и вид) и их средние даты наступления фенофаз. Чтобы получить, например, самые ранние сроки наступления интересующих фенофаз, вместо Avg нужно поставить Min, и, наоборот, для получения поздних - Мах. В поиске по нескольким полям или для отбора записей можно использовать фильтры. Часто используемые фильтры лучше сохранять как запрос таким образом, чтобы в одном столбце выводились данные из нескольких полей. Для объединения полей "Семейство", "Род" и "Вид" в один столбец достаточно ввести новое вычисляемое поле с названием: Выражение 1:[Семейство]\&", "\&[Род]\&", "\&[Вид]. После выполнения запроса нам останется лишь изменить подпись этого поля на "Растение".

Ввод и редактирование записей можно производить непосредственно в исходных таблицах. При правильно сформированных связях между таблицами Access не дает возможности внесения записи во 2 и 3 таблицы, если нет соответствующей записи для этого растения в 1 ("Каталоге"). То есть заполнение таблиц идет в следующей последовательности: в начале одна запись в 1 таблице, где ей присваивается автоматически "Код растения", затем этот "Код растения" повторяется нами во 2 и 3 таблице, и только после этого вносятся все записи, относящиеся $\mathbf{K}$ этому растению в таблицах. Это же справедливо и для удаления записей. Чтобы удалить запись в 1 таблище, нам придется сначала удалить все записи во 2 и 3.

Внесение новьх записей непосредственно в исходные таблицы довольно неэффективно, так как записи вьххдят за границу экрана и перемещение по ним занимает много времени. Поэтому мы сформировали 3 запроса, по одному к каждой таблице, на основе которьх позднее были созданы формы для редактирования и добавления новых записей в исходные таблицы. Более полную информацию по созданию форм можно получить из литературньх источников [3]. В конструкторе формы мы расположили все поля компактно, так чтобы они все помещались на экране. Перемещение по полям назначили по Тab. В результате были получены формы, процесс внесения данньх в которые значительно сократился. Кроме того, перемещение по форме при помощи так называемых "горячих" клавиш дает наглядное представление всех данньх, относящихся к выбранному растению.

Созданные нами формы относятся к разряду простьх. Следующий этап - сделать сложную форму, в которой бы наглядно была представлена полная информация по описанию растения (из таблицы "Каталог") и данные из таблиц "Инвентаризация" или "Фенология". Такая форма называется составной. То есть на основании 2 и 3 таблиц (или запросов к ним) составляются подчиненные формы, которые позднее внедряются в главную, составленную из таблицы "Каталог" (или запроса к ней). В форме в верхней части представлены данные описательного характера по выбранному растению, а в нижней части - данные, например, инвентаризации по годам для этого растения в виде таблицы. Просмотр всех данных по растениям или 
внесение информации по новым растениям теперь стали гораздо удобнее. После просмотра или выбора определенного растения формы можно распечатать.

Работа с формами существенно облегчается за счет использования макрокоманд. В Access имеются более 40 макрокоманд, которые можно включать в макросы. Макрокоманды выполняют такие действия, как открытие таблиц и форм, выполнение запросов, выбор опший из меню и др. Один макрос может содержать несколько макрокоманд. Например, чтобы облегчить работу с нашими простьми формами для редактирования имеющихся и внесения новьх записей в наши исходные 3 таблицы, мы создали несколько простейших макросов, которые выполняются при нажатии кнопки. В форме "Каталог" (сформированной на основе таблицы "Каталог" или запроса к ней) мы поместили две кнопки: "Новая запись" и "Переход в Инвентаризацию". При нажатии первой предоставляется возможность внесения новой записи, а при помощи второй запускается групповой макрос ( на рисунке Макрос 1), который автоматически: вопервьх, сохраняет введенную запись, во-вторьх, закрывает форму "Каталог" и, в третьих, открывает форму "Инвентаризация".

В форме "Инвентаризация" тоже созданы аналогичные кнопки, только при помощи второй уже закрывается форма "Инвентаризация" и открывается "Фенология". В форме "Фенология" расположены соответствующие кнопки: "Новая запись" и "Переход в таблицу Каталог". Последняя активизирует Макрос 3, закрывающий форму "Фенология" и открывающий таблицу "Каталог", чтобы оператор, который будет заниматься заполнением БД, на начальном этапе мог убедиться в правильном заполнении исходных таблищ. Оснащение кнопками форм может проходить индивидуально в зависимости от потребностей исследователя.

\section{ЗАКЛЮЧЕНИЕ}

Освоение оболочки Access показало, что возможно успешное ее использование в области хранения биологической информации.
Из пироких возможностей, предоставляемых этой оболочкой, были подробно рассмотрены лишь некоторые варианты организации и структуриализации БД по растениям, находящимся в коллекциях ботанического сада: внесение новой информации, дополнение и редактирование старой, наглядное представление всей информации для выбранного растения или группы растений в виде простых и сложньх форм, формирование и использование запросов к исходным таблицам, дополнение форм к макросам и др. Это исследование подтвердило высокую эффективность использования Access для организации БД коллекций растений для последующей обработки и систематизации информации. Опыт работы с оболочкой Access показал, что работать с ней может практически любой человек, а не только квалифицированный программист. Тем более, что русифищированная версия предоставляет возможность пользоваться карточками подсказки при возникновении определенньх трудностей на любом этапе создания БД.

\section{ЛИТЕРАТУРА}

1. Кузьмин А. В., Фридман А. Я. Исследовательская база данньх для решения задач математического моделирования динамики лесньх экосистем по интегральньм параметрам // Вычислительный эксперимент и моделирование в системах "технологические процессы - природные комплексы". Апатиты, 1992. С. 87-91.

2. Манс В. Microsoft Access 2. Локализованная версия: Пер. с нем. М.: БИНОМ, 1995. 208 с.: ил.

3. Вейскас Д. Эффективная работа с Microsoft Access 2: Пер. с англ. СПб.: Питер, 1995. 864 с.: ил.

In this article the results of creation the database of collectional funds of plants in Polar-alpine botanical garden-institute on the basis of Access 2 has been adduced. It has been noted the possibilities of search of necessary information, entering new and editing existing data. 


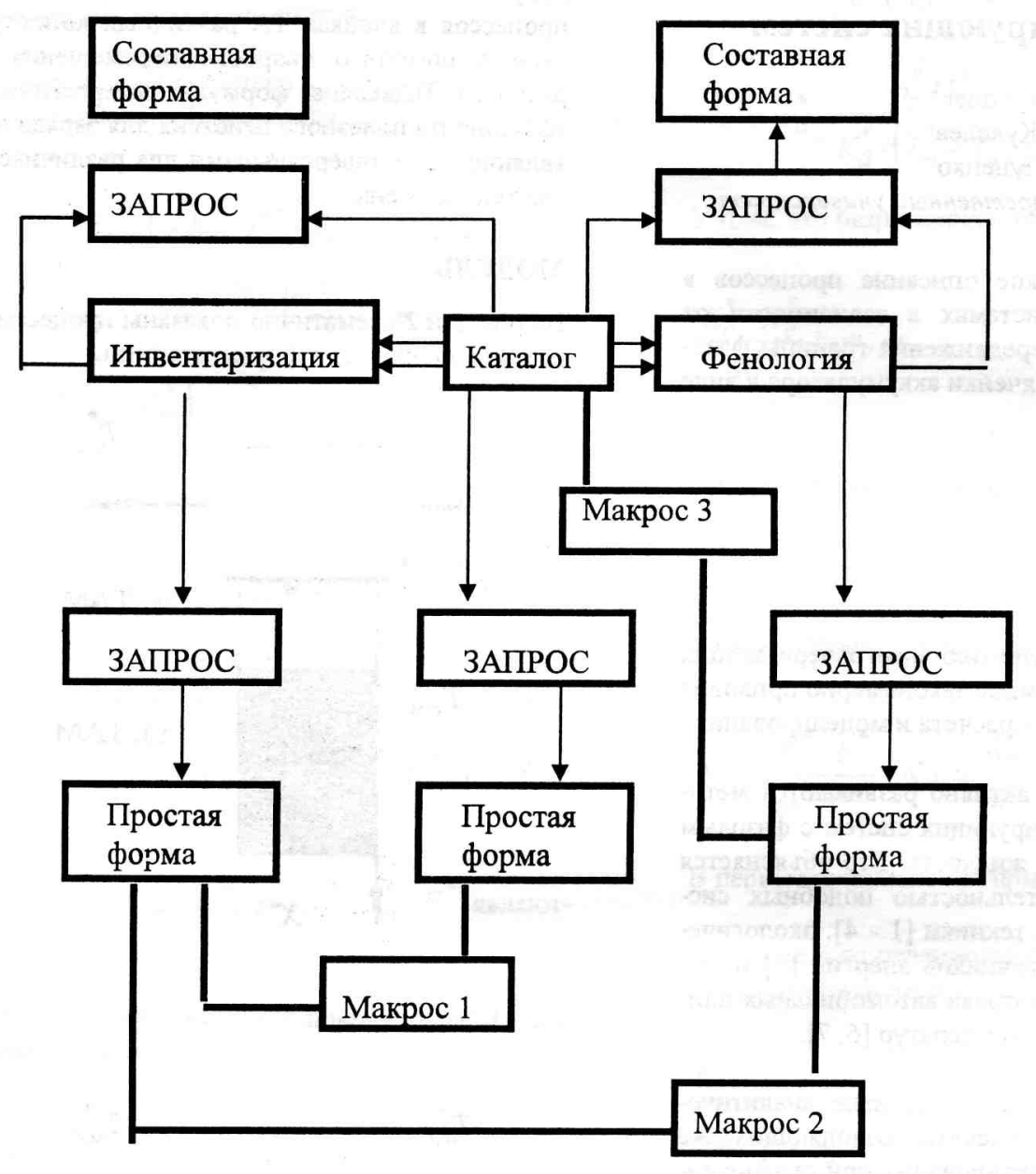

Рис. Структура базы данньх 